\title{
XPA expression is a predictive marker of the effectiveness of neoadjuvant chemotherapy for locally advanced uterine cervical cancer
}

\author{
TAKUMA WADA $^{1,2}$, TAKESHI FUKUDA ${ }^{1}$, MASAHIRO SHIMOMURA $^{1}$, YUTA INOUE $^{1}$, \\ MASARU KAWANISHI ${ }^{1}$, REIKO TASAKA ${ }^{1}$, TOMOYO YASUI ${ }^{1}$, KAZUO IKEDA $^{2}$ and TOSHIYUKI SUMI ${ }^{1}$ \\ Departments of ${ }^{1}$ Obstetrics and Gynecology, and ${ }^{2}$ Anatomy and Regenerative Biology, \\ Osaka City University Graduate School of Medicine, Osaka 545-8585, Japan
}

Received September 23, 2017; Accepted December 11, 2017

DOI: $10.3892 / \mathrm{ol} .2018 .7810$

\begin{abstract}
The standard treatment for locally advanced uterine cervical cancer is concurrent chemoradiotherapy. Successful neoadjuvant chemotherapy (NAC) may reduce tumor size and facilitate a hysterectomy, thereby improving the prognosis for patients with locally advanced cervical cancer. In contrast, unsuccessful NAC may worsen the prognosis because if a hysterectomy is not possible, the change in treatment plan may delay the initiation of core treatment. Therefore, there is a need to identify biomarkers that predict the efficacy of NAC in patients with uterine cervical cancer. The xeroderma pigmentosum complementation group A (XPA) protein serves a major role in nucleotide excision repair, which is a key DNA damage response pathway involved in cisplatin resistance. In the present study, the association between XPA expression in tumor tissue and the efficacy of NAC for locally advanced uterine cervical cancer was investigated. Data from 56 patients aged $<70$ years with locally advanced uterine cervical cancer (FIGO stages IIIA or IIIB) who were classified into two groups based on effective $(n=31)$ and ineffective $(n=25)$ responses to NAC treatment was evaluated. Tumor tissue samples were obtained by punch biopsy prior to NAC and XPA expression was examined immunohistochemically and scored using a weighted scoring system. In addition, the effects of RNA interference-mediated downregulation of XPA on the cisplatin sensitivity of uterine cervical cancer cells was investigated in vitro. It was revealed that the NAC effective group had significantly lower weighted XPA scores than the NAC ineffective group $(\mathrm{P}=0.001)$. Similarly, low tumor
\end{abstract}

Correspondence to: Dr Takeshi Fukuda, Department of Obstetrics and Gynecology, Osaka City University Graduate School of Medicine, 1-4-3 Asahimachi, Abeno-ku, Osaka 545-8585, Japan E-mail: takeshif@med.osaka-cu.ac.jp

Key words: uterine cervical cancer, xeroderma pigmentosum complementation group A, neoadjuvant chemotherapy, platinum resistance, predictive marker expression of XPA was significantly associated with higher sensitivity to NAC $(\mathrm{P}=0.001)$. Additionally, the downregulation of XPA expression in cervical cancer cells significantly increased their sensitivity to cisplatin in vitro. The results of the present study suggest that low XPA expression may be a predictive biomarker of NAC efficacy for patients with locally advanced uterine cervical cancer, which may be helpful for improving their prognosis.

\section{Introduction}

Cervical cancer is a frequent cause of cancer death among women worldwide (1). The standard treatment for locally advanced uterine cervical cancer including International Federation of Gynecology and Obstetrics (FIGO) stage IIIA, IIIB, and IVA cancer consists Platinum-based concurrent chemoradiotherapy (CCRT) (2-4). However, the prognosis of these patients is poor, and the 5-year survival is $<60 \%(5,6)$.

Successful neoadjuvant chemotherapy (NAC) can reduce tumor size in patients with locally advanced cervical cancer, thereby facilitating hysterectomy and improving the prognosis (7). However, the prognosis worsens if NAC is unsuccessful, because hysterectomy may no longer be practicable and the switch to radiotherapy may delay the initiation of the core treatment (8-10). Therefore, there is an urgent need to identify predictive biomarkers of NAC efficacy for patients with locally advanced uterine cervical cancer (10-14).

The antineoplastic activity of cisplatin is primarily due to its ability to induce DNA damage, particularly intrastrand DNA crosslinks, which leads to apoptosis (15). Nucleotide excision repair (NER) is a pathway that identifies and repairs intrastrand DNA crosslinks. Tumor sensitivity to cisplatin has been associated with a decrease in the induction of DNA repair (16). Consistent with this, overexpression of NER proteins confers resistance to platinum-based drugs $(17,18)$. The xeroderma pigmentosum complementation group A (XPA) protein is an indispensable factor for NER. Several reports have shown that XPA recognizes and verifies DNA damage sites, stabilizes repair intermediates, and contributes to the induction of other NER-associated factors (19-24). XPA expression has been reported to correlate with the resistance 
of nasopharyngeal carcinoma and lung cancer cell lines to platinum drugs (17-25). However, the role of XPA in the response of uterine cervical cancer cell lines and uterine cervical cancer patients to cisplatin is not clear.

Here, we sought to determine the utility of XPA expression as a predictive biomarker by investigating the relationship between tumor expression of XPA and the efficacy of NAC for locally advanced uterine cervical cancer.

\section{Materials and methods}

Patients and tissue samples. We evaluated 56 patients with locally advanced uterine cervical cancer (FIGO stages IIIA and IIIB). All patients were $<70$ years of age and were first treated at Osaka City University Hospital (Osaka, Japan) between April 1995 and March 2010. Tumor tissue samples were obtained by punch biopsy before NAC. Patients were classified into two groups based on the response to NAC: Patients who were successfully treated with NAC, underwent hysterectomy, and received radiation therapy $(\mathrm{NAC}+\mathrm{OP}+\mathrm{R}$ group; $\mathrm{n}=31)$, and patients who were unsuccessfully treated with NAC and received only radiation therapy $(\mathrm{NAC}+\mathrm{R}$ group; $\mathrm{n}=25)$. Balloon-occluded arterial infusion chemotherapy for NAC is performed for all patients. We infused Cisplatin (Bristol-Myers Squibb, Tokyo, Japan) intra-arterially through the catheters over $30 \mathrm{~min}$. Cisplatin was administered three times at doses of 50,75 or $100 \mathrm{mg} / \mathrm{m}^{2}$, depending on the patient's age and renal function (26).

Written informed consent was obtained from all patients prior to tumor biopsy. The study was approved by the institutional review board of Osaka City University Hospital (IRB no. 3526).

Immunohistochemical staining. XPA protein expression was examined in four-micrometre sections from paraffin-embedded tissue samples using a mouse monoclonal antibody against XPA (cat no. sc-28353; Santa Cruz Biotechnology, Inc., Dallas, TX, USA) and a Dako LSAB2 Peroxidase kit (cat no. K0675; Agilent Technologies, Santa Clara, CA, USA). After routine deparaffnization and rehydration, sections were immersed in $3 \%$ hydrogen peroxide at room temperature for $10 \mathrm{~min}$ to block endogenous peroxidase activity. Heat-mediated antigen retrieval was performed with $10 \mathrm{mM}$ citrate buffer ( $\mathrm{pH}$ 6.0) by an autoclave at $110^{\circ} \mathrm{C}$ for $20 \mathrm{~min}$. After washing with phosphate-buffered saline (PBS), tumor tissue sections were incubated with a 1:100 dilution of the anti-XPA antibody overnight at $4^{\circ} \mathrm{C}$. Next, sections were washed in PBS for $15 \mathrm{~min}$ and then incubated for $10 \mathrm{~min}$ with biotinylated goat anti-mouse and anti-rabbit immunoglobulin $\mathrm{G}$ secondary antibody (Dako; Agilent Technologies), followed by an incubation with a streptavidin-peroxidase complex, and color was developed using 3,3'-diaminobenzidine used as the chromogen. Finally, tissue sections were counterstained with hematoxylin. A specificity control was prepared in the same manner except the primary antibody was omitted.

The expression levels of XPA were quantitatively analyzed using the weighted score method of Sinicrope et al (27). The mean percentage of stained tumor cells was scored on a scale of 0 to 4 as follows: $0, \leq 5 \% ; 1,5-25 \% ; 2,25-50 \% ; 3,50-75 \%$; and $4,>75 \%$. Staining intensity was classified into three categories:
$1+$, weak; $2+$, moderate; and $3+$, intense. The weighted score for each tissue specimen was determined by multiplying the score of percentage of stained tumor cells by that of staining intensity.

Cell culture. The human uterine cervical cancer cell line Ca Ski (cat no. IFO50007; Japanese Collection of Research Biosources Cell Bank, Osaka, Japan) was cultured in RPMI medium (Gibco; Thermo Fisher Scientific, Waltham, MA, USA) containing 10\% fetal bovine serum (Gibco; Thermo Fisher Scientific) and $1 \%$ penicillin and maintained in a humidified atmosphere with $5 \% \mathrm{CO}_{2}$ at $37^{\circ} \mathrm{C}$.

RNA interference. Small interfering RNA (siRNA) targeted to XPA (5'-GUACCGUAAGACUUGUACUtt, 5'-AGUACAAGU CUUACGGUACtt; cat. no. sc-36853) and a negative control sequence (cat. no. sc-37007) were obtained from Santa Cruz Biotechnology. Cells were seeded in 6-well plates overnight and then transfected with siRNAs using Lipofectamine RNAiMax (Invitrogen, Carlsbad, CA, USA) according to the manufacturer's instructions. The culture medium was changed $24 \mathrm{~h}$ after transfection and cells were used for experiments $24 \mathrm{~h}$ after transfection.

RNA extraction and reverse-transcription-quantitative polymerase chain reaction $(R T-q P C R)$. Total RNA was extracted from the $\mathrm{Ca}$ Ski cells using an RNeasy Mini kit (QIAGEN GmbH, Hilden, Germany) according to the instruction of the manufacturer. RNA was reverse transcribed using a High Capacity cDNA Reverse Transcription kit (Applied Biosystems; Thermo Fisher Scientific). PCR was performed using a TaqMan Gene Expression Assay (Applied Biosystems; Thermo Fisher Scientific) and an Applied Biosystems 7500 Fast Real-Time PCR System. XPA mRNA levels were normalized to glyceraldehyde 3-phosphate dehydrogenase (GAPDH) mRNA in the same samples. TaqMan probes were Hs00902270_m1 for XPA and Hs99999905_m1 for GAPDH.

Chemosensitivity assay. The sensitivity of Ca Ski cells to cisplatin was examined using a Cell Counting kit-8 (CCK-8; Dojindo Molecular Technologies, Kumamoto, Japan). Cells were transfected with negative control or XPA-specific siRNAs as described above and then seeded into 96-well tissue culture plates at $2 \times 10^{3}$ cells/well. After $24 \mathrm{~h}$, the culture medium was removed and vehicle or cisplatin $(0-10 \mu \mathrm{g} / \mathrm{ml})$ was added for $48 \mathrm{~h}$. Subsequently, $10 \mu \mathrm{l} /$ well CCK-8 was added and the plates were incubated for $2 \mathrm{~h}$. The absorbance at $450 \mathrm{~nm}$ was then assesed with a microplate reader (Corona Electric, Ibaraki, Japan). Dose-response curves were constructed of the percentage viable cells compared with untreated cells.

Statistical analysis. All statistical analyses were conducted with SPSS software version 21.0 (IBM SPSS, Armonk, NY, USA). Data are presented as the mean \pm standard deviation in the tables and as the mean \pm standard error in the figures. Kaplan-Meier plots and log-rank analyses were used for prognostic analysis. Weighted scores were compared using the Mann-Whitney 
Table I. Characteristics of the patients in the NAC effective and ineffective groups.

\begin{tabular}{lccc}
\hline Characteristic & $\begin{array}{c}\text { NAC } \\
\text { effective }\end{array}$ & $\begin{array}{c}\text { NAC } \\
\text { ineffective }\end{array}$ & P-value \\
\hline $\begin{array}{l}\text { No. of patients } \\
\text { Age (years) }\end{array}$ & 31 & 25 & \\
Mean \pm SD & $48.9 \pm 13.2$ & $52.3 \pm 11.5$ & $0.317^{\mathrm{a}}$ \\
Range & $24-69$ & $36-68$ & \\
FIGO stage & & & $0.397^{\mathrm{b}}$ \\
IIIA & 1 & 0 & \\
IIIB & 30 & 25 & \\
Histology & & & $0.433^{\mathrm{b}}$ \\
SCC & 27 & 21 & \\
A & 4 & 3 & \\
AS & 0 & 1 & $0.956^{\mathrm{a}}$ \\
Tumor size $(\mathrm{mm})$ & & & \\
Mean \pm SD & $41.1 \pm 22.7$ & $41.4 \pm 23.8$ & \\
\hline
\end{tabular}

aStudent's t-test; ${ }^{\mathrm{b}} \chi^{2}$ test; NAC, neoadjuvant chemotherapy; FIGO, International Federation of Gynecology and Obstetrics; SCC, squamous cell carcinoma; A, adenocarcinoma; AS, adenosquamous carcinoma; SD, standard deviation. Data are the number of patients, unless indicated.

Table II. Weighted scores for XPA expression in the NAC effective and ineffective groups.

\begin{tabular}{lcc}
\hline & \multicolumn{2}{c}{ No. of patients $^{\text {Weighted score }}$} \\
\cline { 2 - 3 } NAC effective $^{\mathrm{a}}$ & NAC ineffective $^{\mathrm{b}}$ \\
\hline 0 & 3 & 0 \\
1 & 4 & 1 \\
2 & 4 & 1 \\
3 & 4 & 0 \\
4 & 6 & 6 \\
6 & 5 & 4 \\
8 & 2 & 5 \\
9 & 3 & 3 \\
12 & 0 & 5 \\
Total & 31 & 25 \\
Weighted score (mean) & 3.90 & 7.12 \\
\hline
\end{tabular}

${ }^{a}$ The NAC effective group underwent neoadjuvant chemotherapy, surgery, and radiotherapy. ${ }^{\text {b}}$ The NAC ineffective group underwent neoadjuvant chemotherapy and radiotherapy only. NAC, neoadjuvant chemotherapy.

$\mathrm{U}$ test. Student's t-test was used for comparison of significant differences between group means, and $\chi^{2}$ tests were used for identification of the association between group categorical variables. $\mathrm{P}<0.05$ was considered to indicate a statistically significant difference.

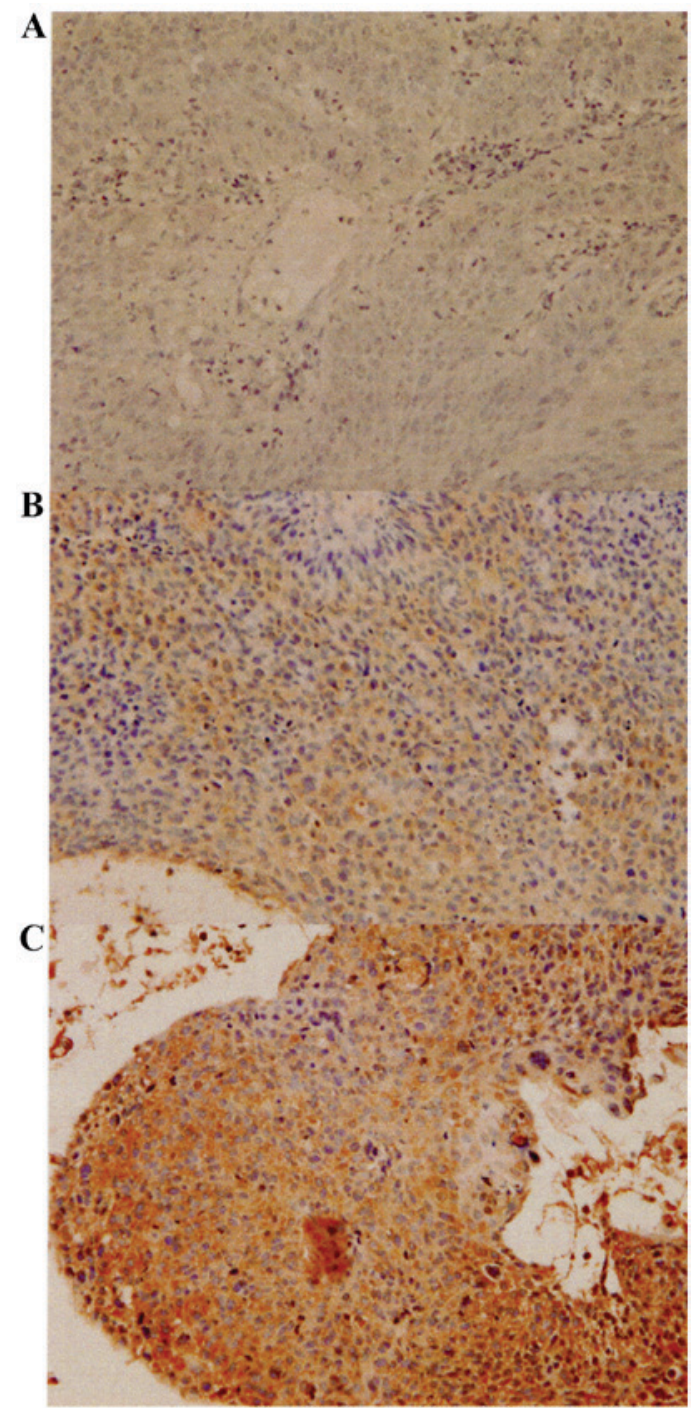

Figure 1. Immunohistochemical staining of XPA in locally advanced cervical cancer. (A) Negative control staining performed without primary antibody. (B and C) Representative sections stained with a primary antibody against XPA showing scores of 6 (B) and 12 (C). Sections were counterstained with hematoxylin. Magnification, x400. XPA, xeroderma pigmentosum complementation group $\mathrm{A}$.

\section{Results}

Patient characteristics. A total of 56 patients with locally advanced uterine cervical cancer were divided into two groups based on their response to therapy: The NAC effective group (NAC + OP + R group; $\mathrm{n}=31$ ) and the NAC ineffective group (NAC $+\mathrm{R}$ group; $\mathrm{n}=25$ ). Table I shows the patients' clinicopathological characteristics. No statistically significant differences were observed between the two groups.

XPA expression in uterine cervical cancer tissue. XPA was expressed in both the nuclei and cytoplasm of the tumor cells (Fig. 1). Table II shows the weighted scores for XPA tissue staining. The mean weighted score of the NAC ineffective group was significantly higher than that of the NAC effective group (7.12 and 3.90, respectively; $\mathrm{P}=0.001$ ) (Fig. 2 and Table II). Of the 56 patients, 17 had weighted scores of $0-3$ (designated low expression) and 39 had weighted scores of 
Table III. Characteristics of patients in the low and high XPA expression groups.

\begin{tabular}{|c|c|c|c|}
\hline Characteristic & $\begin{array}{c}\text { XPA } \\
\text { expression } \\
(\leq 3 \text { score })\end{array}$ & $\begin{array}{c}\text { XPA } \\
\text { expression } \\
(\geq 4 \text { score })\end{array}$ & P-value \\
\hline Number of patients & 17 & 39 & \multirow{4}{*}{$0.808^{\mathrm{a}}$} \\
\hline \multicolumn{3}{|l|}{ Age (years) } & \\
\hline Mean \pm SD & $49.8 \pm 13.6$ & $49.8 \pm 13.6$ & \\
\hline Range & $24-68$ & $24-69$ & \\
\hline \multicolumn{3}{|l|}{ FIGO stage } & \multirow[t]{3}{*}{$0.505^{\mathrm{b}}$} \\
\hline IIIA & 0 & 1 & \\
\hline IIIB & 17 & 38 & \\
\hline \multicolumn{3}{|l|}{ Histology } & \multirow[t]{4}{*}{$0.759^{b}$} \\
\hline $\mathrm{SCC}$ & 15 & 33 & \\
\hline A & 2 & 5 & \\
\hline AS & 0 & 1 & \\
\hline \multicolumn{3}{|l|}{ Tumor size (mm) } & \multirow[t]{2}{*}{$0.470^{\mathrm{a}}$} \\
\hline Mean \pm SD & $44.6 \pm 18.5$ & $39.8 \pm 24.8$ & \\
\hline \multicolumn{4}{|c|}{$\begin{array}{l}\text { aStudent's t-test; }{ }^{b} \chi^{2} \text { test; XPA, xeroderma pigmentosum comple- } \\
\text { mentation group A; FIGO, International Federation of Gynecology } \\
\text { and Obstetrics; SCC, squamous cell carcinoma; A, adenocarcinoma; } \\
\text { AS, adenosquamous carcinoma; SD, standard deviation. Data are the } \\
\text { number of patients, unless indicated. }\end{array}$} \\
\hline
\end{tabular}

4-12 (high expression). There were no significant differences in patient characteristics between these two groups (Table III).

NAC effectiveness correlates with XPA expression. Of the 17 patients with low XPA expression, $15(88 \%)$ were in the NAC effective group and $2(12 \%)$ were in the NAC ineffective group. In the high XPA expression group, 16 patients $(41 \%)$ were in the NAC effective group and $23(59 \%)$ were in the NAC ineffective group. Thus, patients in the low XPA expression group were more sensitive to NAC than those in the high XPA expression group $(\mathrm{P}=0.001$, Table IV).

Survival. Overall survival was significantly longer for the NAC effective group than for the NAC ineffective group $(\mathrm{P}<0.001)$ (Fig. 3) and was significantly longer for the low XPA expression group than for the high XPA expression group ( $\mathrm{P}=0.01)$ (Fig. 4).

Knockdown of XPA enhances the sensitivity of a uterine cervical cancer cell line to cisplatin treatment. qRT-PCR analysis of Ca Ski cells confirmed that XPA expression was effectively suppressed by transfection with a specific targeting siRNA but not by a non-targeting control siRNA (Fig. 5). Cells transfected with XPA-specific siRNA were significantly more sensitive to cisplatin than were the control cells $(\mathrm{P}<0.05)$ (Fig. 6).

\section{Discussion}

CCRT is considered the standard treatment for patients with locally advanced uterine cervical cancer. Effective NAC
Table IV. Number of patients with low and high XPA expression in the NAC effective and NAC ineffective groups.

\begin{tabular}{lccc}
\hline & \multicolumn{3}{c}{ Number of patients (\%) } \\
\cline { 2 - 4 } XPA expression & $\begin{array}{c}\text { NAC + OP + R } \\
\mathrm{n}=31\end{array}$ & $\begin{array}{c}\text { NAC + R } \\
\mathrm{n}=25\end{array}$ & P-value \\
\hline $\begin{array}{l}\text { Low expression } \\
(\leq 3 \text { score })\end{array}$ & $15(88 \%)$ & $2(12 \%)$ & $0.001^{\mathrm{a}}$ \\
$\begin{array}{l}\text { High expression } \\
(\geq 4 \text { score })\end{array}$ & $16(41 \%)$ & $23(59 \%)$ & \\
\hline
\end{tabular}

${ }^{\mathrm{a}} \chi^{2}$ test; $\mathrm{NAC}+\mathrm{OP}+\mathrm{R}$, neoadjuvant chemotherapy + surgery + radiotherapy; NAC+R, neoadjuvant chemotherapy + radiotherapy; $\mathrm{XPA}$, xeroderma pigmentosum complementation group A.

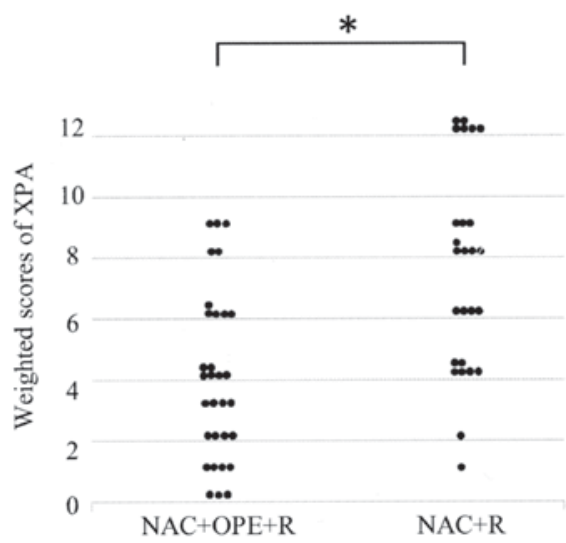

Figure 2. Weighted scores for XPA expression in tumor samples from patients with locally advanced cervical cancer. ${ }^{*} \mathrm{P}=0.001$ (Mann-Whitney $\mathrm{U}$ test). $\mathrm{NAC}+\mathrm{OP}+\mathrm{R}$, neoadjuvant chemotherapy + surgery + radiotherapy; $\mathrm{NAC}+\mathrm{R}$, neoadjuvant chemotherapy + radiotherapy; XPA, xeroderma pigmentosum complementation group $\mathrm{A}$.

can reduce the tumor size, allowing the patient to undergo hysterectomy and potentially improving their prognosis (7). However, the prognosis can worsen if NAC is unsuccessful because the change in treatment plan from surgery to radiotherapy can delay implementation of the core treatment (8-10). Therefore, it is important to identify biomarkers that can predict the efficacy of NAC in patients with locally advanced uterine cervical cancer.

The antitumor mechanism of platinum-containing drugs such as cisplatin results from covalent binding to DNA and formation of platinum-DNA adducts, which interfere with DNA replication and ultimately induce apoptosis (28). Although platinum-based chemotherapy often has good initial efficacy, cancer cells may acquire resistance to this therapy. Some of the potential mechanisms of resistance are reduced intracellular accumulation of cisplatin (29-31), inactivation of apoptotic pathways (32), increased DNA damage repair capacity $(18,33)$, increased detoxification of cisplatin $(34)$, and other epigenetic changes occurring at the molecular and cellular levels $(35,36)$. Among these, NER, which mediates DNA damage repair, is believed to be one the most crucial determinants (18). XPA is an indispensable factor for 


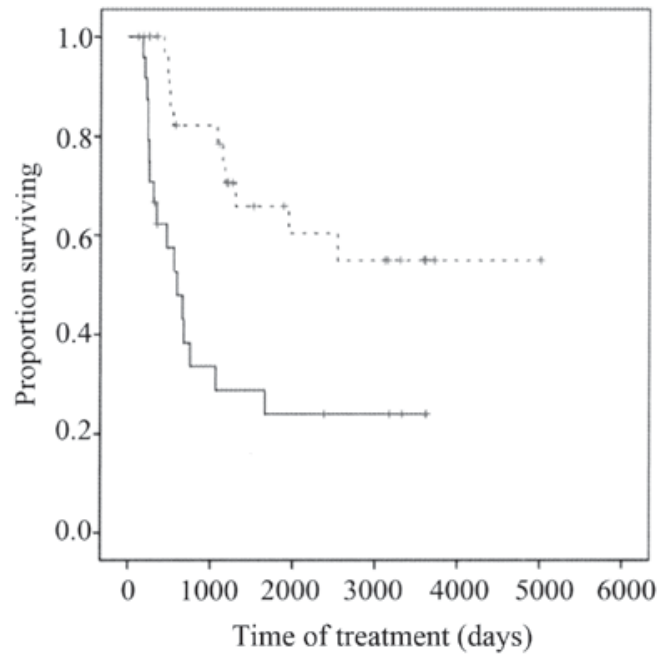

Figure 3. Overall survival rate of the NAC effective group (dashed line, $n=31$ ) and NAC ineffective group (solid line, $\mathrm{n}=25$ ). $\mathrm{P}<0.001$ (Kaplan-Meier and log-rank tests). NAC, neoadjuvant chemotherapy.

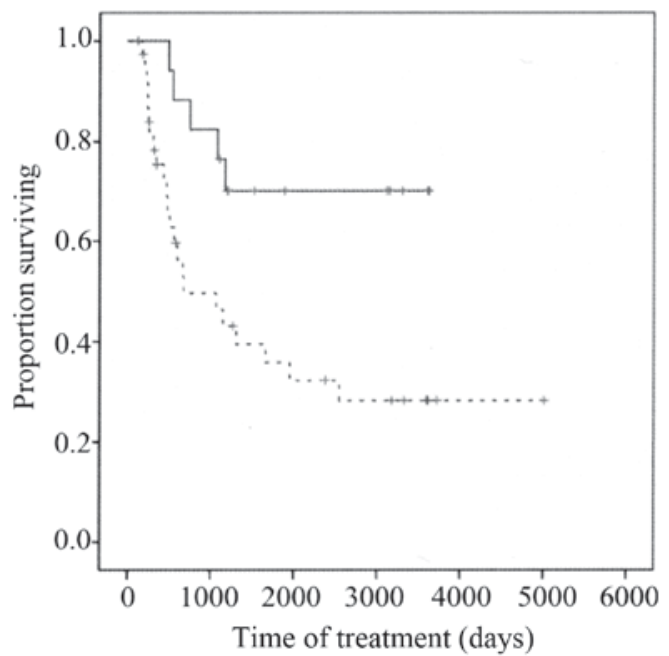

Figure 4. Overall survival of the low XPA expression group (solid line, $\mathrm{n}=17$ ) and high XPA expression group (dashed line, $\mathrm{n}=39$ ). $\mathrm{P}=0.01$ (Kaplan-Meier and log-rank tests). XPA, xeroderma pigmentosum complementation group A.

NER $(17,18)$. Several reports have shown that XPA mediates the initial recognition and verification of DNA lesions, stabilizes repair intermediates, and is involved in the induction of other NER factors (19-24). Therefore, it is likely that upregulation of XPA expression would increase platinum resistance. Indeed, XPA expression has been reported to correlate with the resistance of nasopharyngeal carcinoma and lung cancer cell lines to platinum-based therapy $(17,18,25)$.

The present study reveals a significant relationship between XPA expression and the effectiveness of NAC in patients with locally advanced uterine cervical cancer. Patients with low XPA expression tended to be more sensitive to NAC and underwent surgery after NAC. This is consistent with the longer overall survival times of the low XPA expression group and NAC effective group compared with the high XPA expression group and NAC ineffective group, respectively. We also found that downregulation of XPA expression increased the

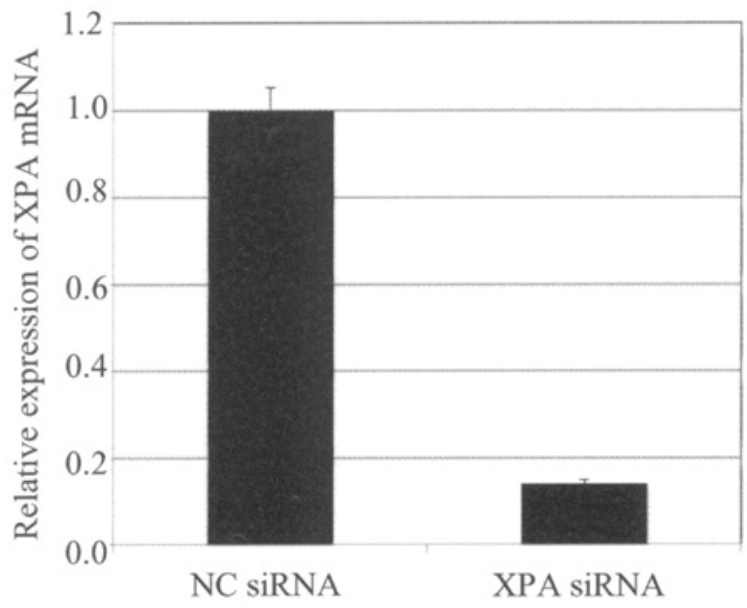

Figure 5. Reverse transcription-quantitative polymerase chain reaction analysis of $X P A$ mRNA expression levels in the uterine cervical cancer cell line $\mathrm{Ca}$ Ski after transfection with control or $X P A$-targeting siRNAs. mRNA levels were normalized to $G A P D H$. NC, negative control; XPA, xeroderma pigmentosum complementation group A; siRNA, small interfering RNA; $G A P D H$, glyceraldehyde 3-phosphate dehydrogenase.

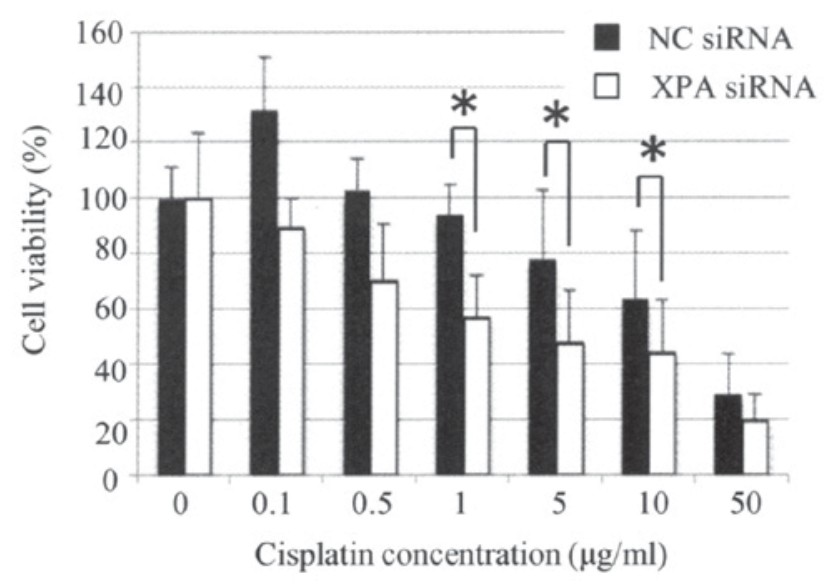

Figure 6. Cell viability of Ca Ski cells transiently transfected with control or $X P A$-targeting siRNAs and then incubated with the indicated concentrations of cisplatin for $24 \mathrm{~h} .{ }^{*} \mathrm{P}<0.05$ (Student's t-test). NC, negative control; XPA, xeroderma pigmentosum complementation group A; siRNA, small interfering RNA.

cisplatin sensitivity of cultured uterine cervical cancer cells, suggesting that XPA is a cisplatin-resistance factor. This is the first report of a correlation between XPA expression and NAC efficacy for locally advanced uterine cervical cancer. However, this study included only 56 patients. One of the limitations of this study was the small number of patients. We need further investigations with a larger number of cases to know the critical fact.

In summary, XPA expression may be a predictive marker of the effectiveness of NAC for patients with locally advanced uterine cervical cancer. This finding could help to improve the prognosis of these patients.

\section{Acknowledgements}

The authors would like to thank Dr Anne M. O'Rourke, for editing a draft of this manuscript. 


\section{References}

1. Jemal A, Bray F, Center MM, Ferlay J, Ward E and Forman D: Global cancer statistics. CA Cancer J Clin 61: 69-90, 2011.

2. Pecorelli S: Revised FIGO staging for carcinoma of the vulva, cervix and endometrium. Int J Gynaecol Obstet 105: 103-104, 2009.

3. Japan Society of Gynecologic Oncology (eds). Formulation Committee of the Treatment Guidelines for Cervical Cancer, 2011. Kanehara \& Co., Tokyo, 2011 (In Japanese).

4. National Comprehensive Cancer Network. NCCN Clinical Practice Guidelines in Oncology. Cervical Cancer Version II, 2013.

5. Morris M, Eifel PJ, Lu J, Grigsby PW, Levenback C, Stevens RE, Rotman M, Gershenson DM and Mutch DG: Pelvic radiation with concurrent chemotherapy compared with pelvic and para-aortic radiation for high-risk cervical cancer. N Engl J Med 340: 1137-1143, 1999.

6. Eifel PJ, Winter K, Morris M, Levenback C, Grigsby PW, Cooper J, Rotman M, Gershenson D and Mutch DG: Pelvic irradiation with concurrent chemotherapy versus pelvic and para-aortic irradiation for high-risk cervical cancer: An update of radiation therapy oncology group trial (RTOG) 90-01. J Clin Oncol 22: 872-880, 2004

7. Ishiko O, Sumi T, Yasui T, Matsumoto Y, Kawamura N, Ogita S, Kamino T, Nakamura K and Yamada R: Balloon-occluded arterial infusion chemotherapy, simple total hysterectomy and radiotherapy as a useful combination-therapy for advanced cancer of the uterine cervix. Oncol Rep 7: 141-144, 2000.

8. Souhami L, Gil RA, Allan SE, Canary PC, Araújo CM, Pinto LH and Silveira TR: A randomized trial of chemotherapy followed by pelvic radiation therapy in stage IIIB carcinoma of the cervix. J Clin Oncol 9: 970-977, 1991.

9. Tattersall MH, Lorvidhaya V, Vootiprux V, CheirsilpaA, Wong F, Azhar T, Lee HP, Kang SB, Manalo A, Yen MS, et al:Randomized trial of epirubicin and cisplatin chemotherapy followed by pelvic radiation in locally advanced cervical cancer. Cervical cancer study group of the asian oceanian clinical oncology association J Clin Oncol 13: 444-451, 1995.

10. Ishiko O, Sumi T, Yasui T, Matsumoto Y, Ogita S, Kaminou T, Nakamura K and Yamada R: Tumor marker and MR imaging criteria for evaluating the efficacy of cyclic balloon-occluded arterial infusion for advanced cancer of the uterine cervix. Oncol Rep 7: 827-830, 2000.

11. Ishiko O, Sumi T, Yoshida H, Ogita S and Yamada R: Expression of apoptosis regulatory proteins in advanced cancer of the uterine cervix after cyclic balloon-occluded arterial infusion chemotherapy. Int J Oncol 18: 1151-1155, 2001.

12. Okamoto E, Sumi T, Misugi F, Nobeyama H, Hattori K, Yoshida H, Matsumoto Y, Yasui T, Honda K and Ishiko O Expression of apoptosis-related proteins in advanced uterine cervical cancer after balloon-occluded arterial infusion chemotherapy as an indicator of the efficiency of this therapy. Int J Mol Med 15: 41-47, 2005.

13. Nobeyama H, Sumi T, Misugi F, Okamoto E, Hattori K, Matsumoto Y, Yasui T, Honda K, Iwai K and Ishiko O: Association of HPV infection with prognosis after neoadjuvant chemotherapy in advanced uterine cervical cancer. Int J Mol Med 14: 101-105, 2004

14. Benedetti Panici P, Bellati F, Manci N, Pernice M, Plotti F, Di Donato V, Calcagno M, Zullo MA, Muzii L and Angioli R: Neoadjuvant chemotherapy followed by radical surgery in patients affected by FIGO stage IVA cervical cancer. Ann Surg Oncol 14: 2643-2648, 2007.

15. Siddik ZH: Cisplatin: Mode of cytotoxic action and molecular basis of resistance. Oncogene 22: 7265-7279, 2003.

16. Köberle B, Grimaldi KA, Sunters A, Hartley JA, Kelland LR and Masters JR: DNA repair capacity and cisplatin sensitivity of human testis tumour cells. Int J Cancer 70: 551-555, 1997.

17. Riedl T, Hanaoka F and Egly JM: The comings and goings of nucleotide excision repair factors on damaged DNA. EMBO J 22: 5293-5303, 2003.

18. Martin LP, Hamilton TC and Schilder RJ: Platinum resistance: The role of DNA repair pathways. Clin Cancer Res 14: 1291-1295, 2008.
19. Yang Z, Roginskaya M, Colis LC, Basu AK, Shell SM, Liu Y, Musich PR, Harris CM, Harris TM and Zou Y: Specific and efficient binding of xeroderma pigmentosum complementation group A to double-strand/single-strand DNA junctions with 3'and/or 5'-ssDNA branches. Biochemistry 45: 15921-15930, 2006

20. Mer G, Bochkarev A, Gupta R, Bochkareva E, Frappier L, Ingles CJ, Edwards AM and Chazin WJ: Structural basis for the recognition of DNA repair proteins UNG2, XPA and RAD52 by replication factor RPA. Cell 103: 449-456, 2000.

21. Batty DP and Wood RD: Damage recognition in nucleotide excision repair of DNA. Gene 241: 193-204, 2000.

22. Liu Y, Liu Y, Yang Z, Utzat C, Wang G, Basu AK and Zou Y: Cooperative interaction of human XPA stabilizes and enhances specific binding of XPA to DNA damage. Biochemistry 44: 7361-7368, 2005.

23. Guzder SN, Sommers CH, Prakash L and Prakash S: Complex formation with damage recognition protein Rad14 is essential for Saccharomyces cerevisiae Rad1-Rad10 nuclease to perform its function in nucleotide excision repair in vivo. Mol Cell Biol 26: 1135-1141, 2006

24. Shell SM and Zou Y: Other proteins interacting with XP proteins. Adv Exp Med Biol 637: 103-112, 2008.

25. Fu X, Hu J, Han HY, Hua YJ, Zhou L, Shuai WD, Du WY, Kuang CM, Chen S, Huang W and Liu RY: High expression of XPA confers poor prognosis for nasopharyngeal carcinoma patients treated with platinum-based chemoradiotherapy. Oncotarget 6: 28478-28490, 2015.

26. Tsuji K, Yamada R, Kawabata M, Mitsuzane K, Sato M, Iwahashi M, Kitayama S and Nakano R: Effect of balloon occluded arterial infusion of anticancer drugs on the prognosis of cervical cancer treated with radiation therapy. Int J Radiat Oncol Biol Phys 32: 1337-1345, 1995.

27. Sinicrope FA, Ruan SB, Cleary KR, Stephens LC, Lee JJ and Levin B: Bcl-2 and p53 oncoprotein expression during colorectal tumorigenesis. Cancer Res 55: 237-241, 1995.

28. Wang D and Lippard SJ: Cellular processing of platinum anticancer drugs. Nat Rev Drug Discov 4: 307-320, 2005.

29. Galluzzi L, Senovilla L, Vitale I, Michels J, Martins I, Kepp O, Castedo M and Kroemer G: Molecular mechanisms of cisplatin resistance. Oncogene 31: 1869-1883, 2012.

30. Ishida S, Lee J, Thiele DJ and Herskowitz I: Uptake of the anticancer drug cisplatin mediated by the copper transporter Ctr1 in yeast and mammals. Proc Natl Acad Sci USA 99: 14298-14302, 2002.

31. Morimoto A, Serada S, Enomoto T, Kim A, Matsuzaki S, Takahashi T, Ueda Y, Yoshino K, Fujita M, Fujimoto M, et al: Annexin A4 induces platinum resistance in a chloride-and calcium-dependent manner. Oncotarget 5: 7776-7787, 2014

32. Wang Q, Shi S, He W, Padilla MT, Zhang L, Wang X, Zhang B and Lin Y: Retaining MKP1 expression and attenuating JNK-mediated apoptosis by RIP1 for cisplatin resistance through miR-940 inhibition. Oncotarget 5: 1304-1314, 2014.

33. Liu RY, Dong Z, Liu J, Yin JY, Zhou L, Wu X, Yang Y, Mo W, Huang W, Khoo SK, et al: Role of eIF3a in regulating cisplatin sensitivity and in translational control of nucleotide excision repair of nasopharyngeal carcinoma. Oncogene 30: 4814-4823, 2011.

34. Mistry P, Kelland LR, Abel G, Sidhar S and Harrap KR: The relationships between glutathione, glutathione-S-transferase and cytotoxicity of platinum drugs and melphalan in eight human ovarian carcinoma cell lines. Br J Cancer 64: 215-220, 1991.

35. Shen DW, Pouliot LM, Hall MD and Gottesman MM: Cisplatin resistance: A cellular self-defense mechanism resulting from multiple epigenetic and genetic changes. Pharmacol Rev 64: 706-721, 2012 .

36. Liu RY, Dong Z, Liu J, Zhou L, Huang W, Khoo SK, Zhang Z, Petillo D, Teh BT, Qian CN and Zhang JT: Overexpression of asparagine synthetase and matrix metalloproteinase 19 confers cisplatin sensitivity in nasopharyngeal carcinoma cells. Mol Cancer Ther 12: 2157-2166, 2013. 